\title{
Calculation of the Proton Affinities of Primary, Secondary, and Tertiary Amines Using Semiempirical and ab initio Methods
}

\author{
Gerhard Raabe, Yuekui Wang, and Jörg Fleischhauer \\ Lehr- und Forschungsgebiet Theoretische Chemie, Institut fur Organische \\ Chemie der Rheinisch-Westfälischen Technischen Hochschule Aachen, \\ Professor-Pirlet-Straße 1, D-52056 Aachen, Germany \\ Reprint requests to either Prof. J. F. gk016fl@ cluster.rz.rwth-aachen.de) \\ or Dr. G. R. Gerd.Raabe@thc.rwth-aachen.de)
}

Z. Naturforsch. 55 a, 687-694 (2000); received June 10, 2000

Presented in part at the 40th Sanibel Symposium, February 26 - March 3, 2000, St. Augustine, Florida, USA.

The proton affinities of some primary, secondary, and tertiary amines have been calculated with different semiempirical and nonempirical quantum chemical methods. We were particularly interested in the question which of the most popular semiempirical methods yield good overall correlations between calculated and experimental values and, therefore, allow a reliable prediction of hitherto unknown proton affinities. We found that some of the most frequently used semiempirical methods result in good correlations only within the groups of primary, secondary and tertiary amines, while the overall correlation is even worse than the one obtained with the noniterative EHT method. Among the more recent methods which allow geometry optimizations (MINDO/3, MNDO, AM1, PM3, MSINDO) the best results have been calculated with the MSINDO method. Testing for the influence of geometry optimization we surprisingly found that two of these methods (MINDO/3, AM1) perform even better when geometry optimizations are omitted and standard bonding parameters are used instead. Superior results, however, have been obtained with the CNDO/2- and the INDO method. Finally, the best correlations between semiempirically calculated and experimental proton affinities have been achieved with the spectroscopic parametrizations of these methods, $\mathrm{CNDO} / 2 \mathrm{~S}$ and INDO/2S, respectively. The correlations resulting in these cases are close to those reached at the ZPE+MP2/6-311++G**//HF/6-311++G** level of ab initio theory and with a comparable DFT method.

A preliminary investigation revealed that an improvement in the semiempirical calculation of proton affinities might be obtained if different $U_{\mu \mu}$ parameters are used for the nitrogen atoms of primary, secondary, and tertiary amines.

Key words: Proton Affinities; Amines; Semiempirical Methods.

\section{Introduction}

One of the most important chemical processes is the protonation reaction. It does not only play an important role in general chemistry but is also of highest physiological relevance. Therefore, a secure computational prediction of proton affinities (PA) is of utmost importance. Since many of the physiologically active compounds are of a size that still prohibits treatment on a reasonable $a b$ initio level, one is confined to semiempirical quantum chemical methods in these cases. Thus, a demand to be made on a reliable quantum chemical semiempirical method is that calculated and measured proton affinities correlate.
In order to see which of the commonly used semiempirical methods fulfill this requirement, we calculated the proton affinities of a variety of organic amines with the PM3 [1], AM1 [2], MNDO [3], MINDO/3 [4], MSINDO [5], CNDO/2 [6], INDO [7], CNDO/2S [8], INDO/2S [9], and the EHT [10] method. In addition we performed calculations with two density functional (DFT) methods. The semiempirical results have been compared not only with experimental values [11] but also with the proton affinities calculated at the ZPE+MP2/6-311++G**//HF/6$311++\mathrm{G}^{* *}$ level of $a b$ intio theory.

We further examined possible reasons for the failure of some semiempirical methods to repro- 
Table 1. Measured $\left(\mathrm{PA}_{\mathrm{ex}}\right)$ and calculated proton affinties (in $\mathrm{kcal} / \mathrm{mol}$ ). The values listed in the column headed 6$311++\mathrm{G}^{* *}$ have been calculated at the ZPE+MP2/6-311++

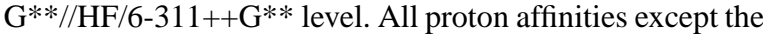
STO3-G values have been calculated for completely optimized geometries.

\begin{tabular}{llccccc}
\hline $\begin{array}{l}\text { No. } \\
\text { ule }\end{array}$ & PA $_{\text {ex }}$ & $6-311++G^{* *}$ & STO-3G & $\begin{array}{c}\text { B-P86/ } \\
\text { TZVP }\end{array}$ & $\begin{array}{c}\text { B-P86/ } \\
\text { SV(P) }\end{array}$ \\
\hline 1 & $\mathrm{NH}_{3}$ & 207.0 & 204.7 & 259.8 & 205.2 & 207.5 \\
2 & $\mathrm{MeNH}_{2}$ & 218.4 & 215.3 & 267.5 & 215.2 & 215.1 \\
3 & $\mathrm{EtNH}_{2}$ & 221.4 & 218.0 & 270.9 & 218.6 & 218.1 \\
4 & $n-\mathrm{PrNH}_{2}$ & 222.8 & 219.0 & 272.4 & 219.5 & 219.1 \\
5 & $n-\mathrm{BuNH}_{2}$ & 223.3 & 219.6 & 273.1 & 220.2 & 218.7 \\
6 & $\mathrm{Me}_{2} \mathrm{NH}^{2}$ & 224.8 & 222.2 & 272.7 & 221.4 & 219.6 \\
7 & $\mathrm{MeEtNH}_{2}$ & 227.3 & 224.6 & 275.4 & 224.0 & 222.3 \\
8 & $\mathrm{Et}_{2} \mathrm{NH}$ & 229.4 & 226.9 & 278.0 & 227.3 & 225.5 \\
9 & $\mathrm{Me}_{3} \mathrm{~N}$ & 228.6 & 226.4 & 276.7 & 224.9 & 221.7 \\
10 & $\mathrm{Me}_{2} \mathrm{EtN}$ & 230.9 & 228.7 & 278.6 & 228.0 & 225.0 \\
11 & $\mathrm{MeEt}_{2} \mathrm{~N}$ & 233.3 & 230.9 & 281.0 & 230.7 & 227.8 \\
12 & $\mathrm{Et}_{3} \mathrm{~N}$ & 235.5 & 233.3 & 283.2 & 233.6 & 230.7 \\
\hline
\end{tabular}

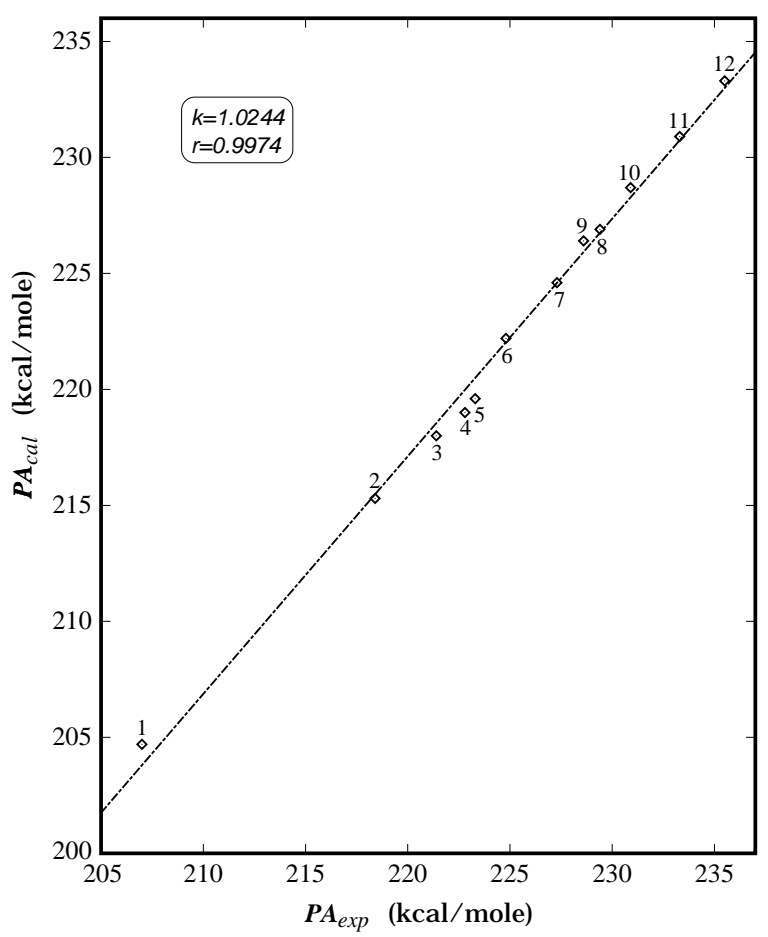

Fig. 1. Plot of calculated proton affinities $\left(\mathrm{PA}_{\mathrm{cal}}, 298 \mathrm{~K}\right.$, ZPE+MP2/6-311++G**//HF/6-311++G**) vs. experimental values $\left(\mathrm{PA}_{\mathrm{exp}}\right)$ in ${ }^{\mathrm{kcal}} / \mathrm{mol}$. (1: $\mathrm{NH}_{3}, 2: \mathrm{MeNH}_{2}, 3: \mathrm{EtNH}_{2}$, 4: $n-\mathrm{PrNH}_{2}$, 5: $n-\mathrm{BuNH}_{2}$, 6: $\mathrm{Me}_{2} \mathrm{NH}$, 7: MeEtNH, 8: $\left.\mathrm{Et}_{2} \mathrm{NH}, 9: \mathrm{Me}_{3} \mathrm{~N}, 10: \mathrm{Me}_{2} \mathrm{EtM}, 11: \mathrm{MeEt}_{2} \mathrm{~N}, 12: \mathrm{Et}_{3} \mathrm{~N}\right)$.

duce the experimentally observed trend and tried to improve the performance of these computa- tional methods in the calculation of proton affinities.

\section{Computational Methods}

All $a b$ initio calculations have been performed using the GAUSSIAN98 suite of quantum chemical routines [12], while TURBOMOLE (version 5) [13] has been employed to obtain the DFT results. The MOPAC6.0 package [14] has been used for the MINDO/3-, MNDO-, AM1-, and PM3 calculations, while the personal computer version of CNINDO [15] has been employed for the CNDO/2- and INDOand the DZDO program [16] for the INDO/2S- and $\mathrm{CNDO} / 2 \mathrm{~S}$ computations. Finally, calculations with the modified SINDO1 method have been performed with the MSINDO (version 1.0) program [17]. The proton affinities have been calculated using the semiclassical approximation $\mathrm{PA}_{\text {cal }}=-\Delta E_{\text {prot }}+5 / 2 R T$. $\Delta E_{\text {prot }}=E_{\text {tot }}\left(\mathrm{BH}^{+}\right)-E_{\text {tot }}(\mathrm{B})$ is the difference between the total energies of the cation $\left(\mathrm{BH}^{+}\right)$and the base (B) and includes the correlation- and zero point vibrational energy for the structures optimized at the $a b$ initio- and the DFT level. Calculated and measured proton affinities are compiled in Tables $1-4$. The corresponding correlation lines are shown in Figures $1-10$.

\section{Results and Diskussion}

$A b$ initio methods including correlation- as well as zero point energy (ZPE) and employing mediumsized basis sets (ZPE+MP2/6-311++G**//HF/6-311 $\left.++\mathrm{G}^{* *}\right)$ allow calculation of proton affinities which agree nicely with the corresponding measured values (Table 1, Figure 1). Although the calculated proton affinities are systematically smaller than their experimentally determined counterparts, the correlation coefficient is 0.9974 and the slope of the least-squares line $(k)$ is close to one. In this case the mean difference between the calculated $\left(\mathrm{PA}_{\mathrm{cal}}\right)$ and measured $\left(\mathrm{PA}_{\mathrm{ex}}\right)$ values $\left(\Delta \mathrm{PA}=\left\langle\left|\mathrm{PA}_{\mathrm{ex}}-\mathrm{PA}_{\text {cal }}\right|\right\rangle\right)$ is $2.8 \mathrm{kcal} / \mathrm{mol}$. Correlations of similar quality have been obtained by Klessinger et $a l$. at the ZPE+MP2(fc)/6-311+G* //HF/6-31G* and ZPE+MP2(fc)/6-311+G**//HF/6$31 \mathrm{G}^{*}$ levels of ab intio theory [18] ${ }^{\text {a) }}$. Moreover, Smith and Radom used the G2(MP2,SVP) method to calculate the proton affinities of $\mathrm{MeNH}_{2}, \mathrm{Me}_{2} \mathrm{NH}, \mathrm{Me}_{3} \mathrm{~N}$,

\footnotetext{
${ }^{a)} \mathrm{fc}=$ frozen core, i.e. core excitations omitted.
} 


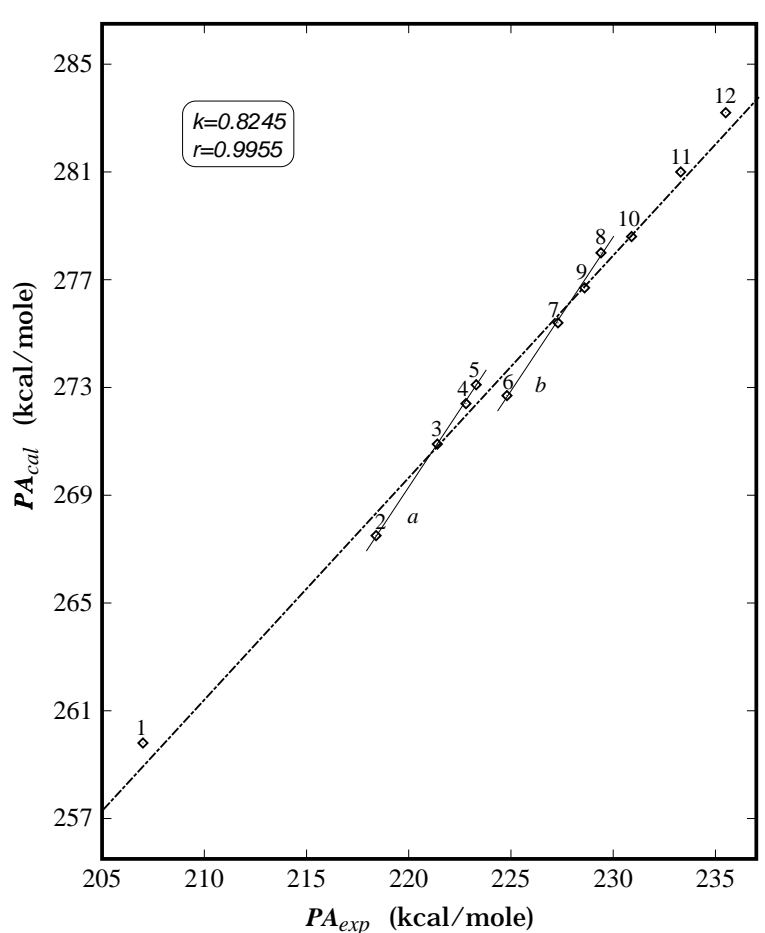

Fig. 2. Plot of calculated proton affinities $\left(\mathrm{PA}_{\mathrm{cal}}, 298 \mathrm{~K}\right.$, HF/STO-3G, standard geometries) vs. experimental values $\left(\mathrm{PA}_{\exp }\right)$ in $\mathrm{kcal} / \mathrm{mol}$. Lines $a$ and $b$ show the correlations within the groups of primary and secondary amines. For numbering of compounds see Figure 1.

and $\mathrm{EtNH}_{2}$ [19]. Their values $(215.1,221.7,227.1$, and $218.2 \mathrm{kcal} / \mathrm{mol}$ ) are essentially identical with our results.

Nonempirical calculations at the Hartree-Fock level employing standard structural parameters [20] and minimal basis sets like STO-3G result in values which also correlate nicely $(r=0.9955)$ with the experimental proton affinities (Fig. 2) although they are much higher than the corresponding experimental values $(\Delta \mathrm{PA}=48.9 \mathrm{kcal} / \mathrm{mol}$, see also [21, 22] $)$. Moreover, the correlations within the groups of the primary (line $a$ ) and secondary amines (line $b$ ) are better than the overall correlation.

Complete geometry optimizations at the DFT level employing the B-P86 functional [23] and a valence triple- $\zeta$ basis set (TZVP) including polarization functions result in an overall correlation $(r=0.9966$, $k=0.9931)$ which is only slightly worse than the one obtained at the ZPE+MP2/6-311++G**//HF/6$311++\mathrm{G}^{* *}$ level of conventional ab initio theory (Table 1, Fig. 3), while the mean difference between

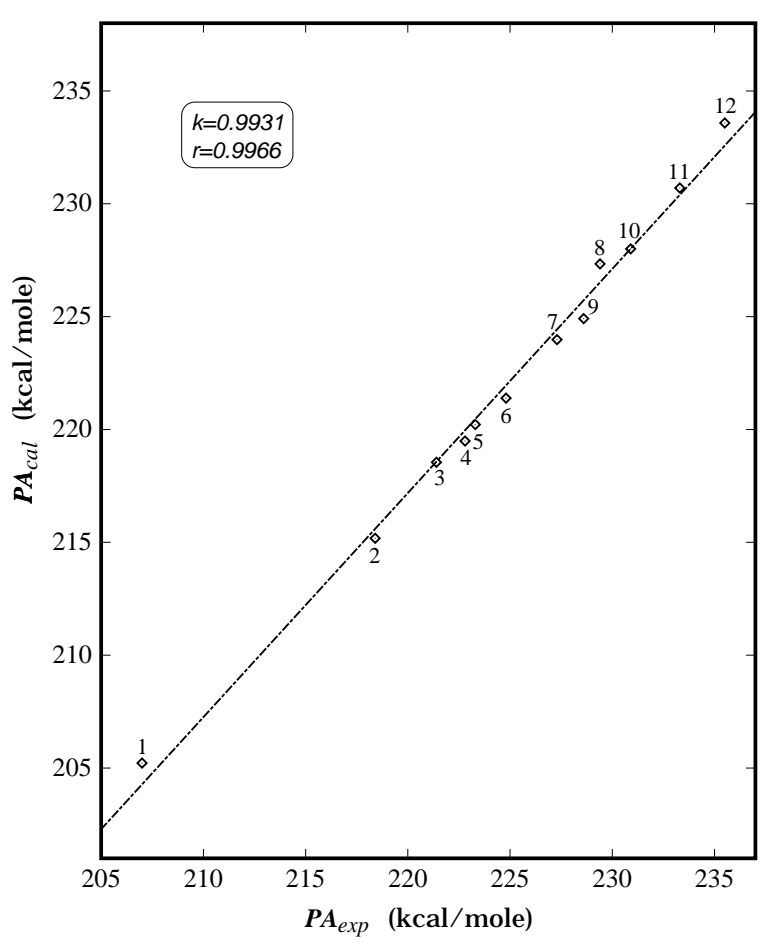

Fig. 3. Plot of calculated proton affinities $\left(\mathrm{PA}_{\mathrm{cal}}, 298 \mathrm{~K}\right.$, ZPE+B-P86/TZVP//B-P86/TZVP) vs. experimental values $\left(\mathrm{PA}_{\text {exp }}\right)$ in $\mathrm{kcal} / \mathrm{mol}$. For numbering of compounds see Figure 1 .

measured and calculated values is the same $(\triangle \mathrm{PA}=$ $2.8 \mathrm{kcal} / \mathrm{mol})$.

To test for the influence of the basis set we repeated these calculations using the same functional but a somewhat smaller split valence basis set including polarization functions for the heavy atoms $(\mathrm{SV}(\mathrm{P}))$. These calculations result in a somewhat less satisfying correlation $(r=0.9867, k=0.7926)$. Moreover, the mean difference between measured and calculated values is somewhat higher $(\Delta \mathrm{PA}=4.4 \mathrm{kcal} / \mathrm{mol})$ and the correlations within the groups of the secondary (line $b$ ) and tertiary amines (line $c$ ) are significantly better than the overall correlations (Table 1, Figure 4).

The results shown in Fig. 5 and listed in Table 2 have been calculated with the most popular semiempirical methods employing fully optimized geometries.

The best correlation between calculated and measured proton affinities has been obtained with the MSINDO method. MINDO/3, MNDO, AM1, and PM3 result in good correlations within the groups 


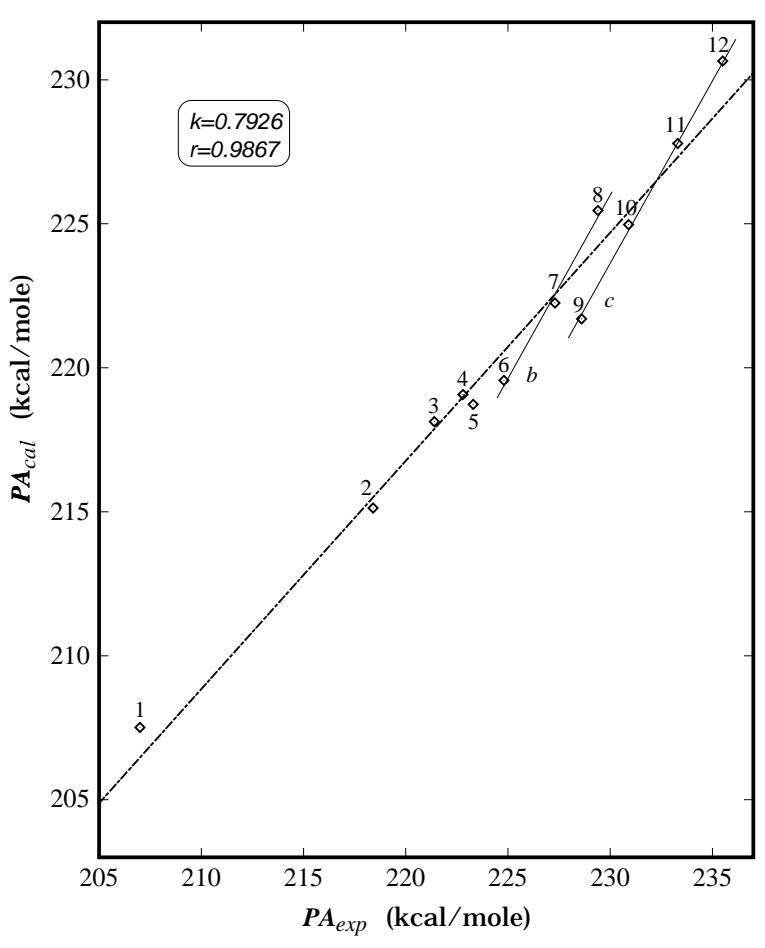

Fig. 4. Plot of calculated proton affinities $\left(\mathrm{PA}_{\mathrm{cal}}, 298 \mathrm{~K}\right.$, $\mathrm{ZPE}+\mathrm{B}-\mathrm{P} 86 / \mathrm{SV}(\mathrm{P}) / / \mathrm{B}-\mathrm{P} 86 / \mathrm{SV}(\mathrm{P}))$ vs. experimental values $\left(\mathrm{PA}_{\text {exp }}\right)$ in $\mathrm{kcal} / \mathrm{mol}$. Lines $b$ and $c$ show the correlations within the groups of secondary and tertiary amines. For numbering of compounds see Figure 1.

of the primary (line $a$ ), secondary (line $b$ ), and tertiary amines (line $c$ ), while the overall correlations are rather poor. The only method besides MSINDO which correctly predicts the order of the proton affinities of the mono-, di-, and trimethyl- and ethyl amines $\left(\mathrm{RNH}_{2}<\mathrm{R}_{2} \mathrm{NH}<\mathrm{R}_{3} \mathrm{~N}\right)$ is AM1 [24], while the overall correlation is still rather poor. PM3 also gives the correct order for the ethyl amines, however the calculated proton affinities of the corresponding methyl compounds erroneously decrease in the order $\mathrm{MeNH}_{2}$ $>\mathrm{Me}_{2} \mathrm{NH}>\mathrm{Me}_{3} \mathrm{~N}$. Both MINDO/3 [21, 25] and MNDO [26] yield proton affinities which increase from the mono- to the dimethyl- and the diethyl compounds. However, with both methods the proton affinities are lower for the tri- than for the dialkyl bases. Thus these two methods yield gas phase proton affinities which correlate with the observed order of basicities in aqueous solution $\mathrm{pk}_{\mathrm{b}}\left(\mathrm{RNH}_{2}\right)$ $>\mathrm{pk}_{\mathrm{b}}\left(\mathrm{R}_{2} \mathrm{NH}\right)<\mathrm{pk}_{\mathrm{b}}\left(\mathrm{R}_{3} \mathrm{~N}\right)$, where $\mathrm{R}=\mathrm{Me}$, Et, $n$-Pr) [27].
Table 2. Measured $\left(\mathrm{PA}_{\mathrm{ex}}\right)$ and calculated proton affinties (in $\mathrm{kcal} / \mathrm{mol}$ ). All proton affinities have been calculated for completely optimized geometries.

\begin{tabular}{lllllllll}
\hline No. & Molecule & $\mathrm{PA}_{\text {ex }}$ & MINDO/3 & MNDO & AM1 & PM3 & MSINDO \\
\hline 1 & $\mathrm{NH}_{3}$ & 207.0 & 178.7 & 157.2 & 158.6 & 198.6 & 225.5 \\
2 & $\mathrm{MeNH}_{2}$ & 218.4 & 184.6 & 158.9 & 160.3 & 196.6 & 241.0 \\
3 & $\mathrm{EtNH}_{2}$ & 221.4 & 189.2 & 161.0 & 162.6 & 198.3 & 247.8 \\
4 & $n$-PrNH $_{2}$ & 222.8 & 190.5 & 161.5 & 163.0 & 198.7 & 250.4 \\
5 & $n$-BuNH $_{2}$ & 223.3 & 191.3 & 161.8 & 163.3 & 198.9 & 251.8 \\
6 & $\mathrm{Me}_{2} \mathrm{NH}_{2}$ & 224.8 & 185.6 & 159.2 & 161.6 & 194.6 & 256.0 \\
7 & $\mathrm{MeEtNH}_{2}$ & 227.3 & 188.6 & 160.8 & 165.2 & 197.6 & 260.0 \\
8 & $\mathrm{Et}_{2} \mathrm{NH}$ & 229.4 & 191.3 & 162.3 & 168.6 & 200.5 & 262.5 \\
9 & $\mathrm{Me}_{3} \mathrm{~N}$ & 228.6 & 184.1 & 158.2 & 162.7 & 193.0 & 270.9 \\
10 & $\mathrm{Me}_{2} \mathrm{EtN}^{2}$ & 230.9 & 186.3 & 159.1 & 166.3 & 196.0 & 273.7 \\
11 & $\mathrm{MeEt}_{2} \mathrm{~N}$ & 233.3 & 188.3 & 159.9 & 169.7 & 199.0 & 276.2 \\
12 & $\mathrm{Et}_{3} \mathrm{~N}$ & 235.5 & 190.8 & 161.0 & 173.5 & 201.6 & 278.6 \\
\hline
\end{tabular}

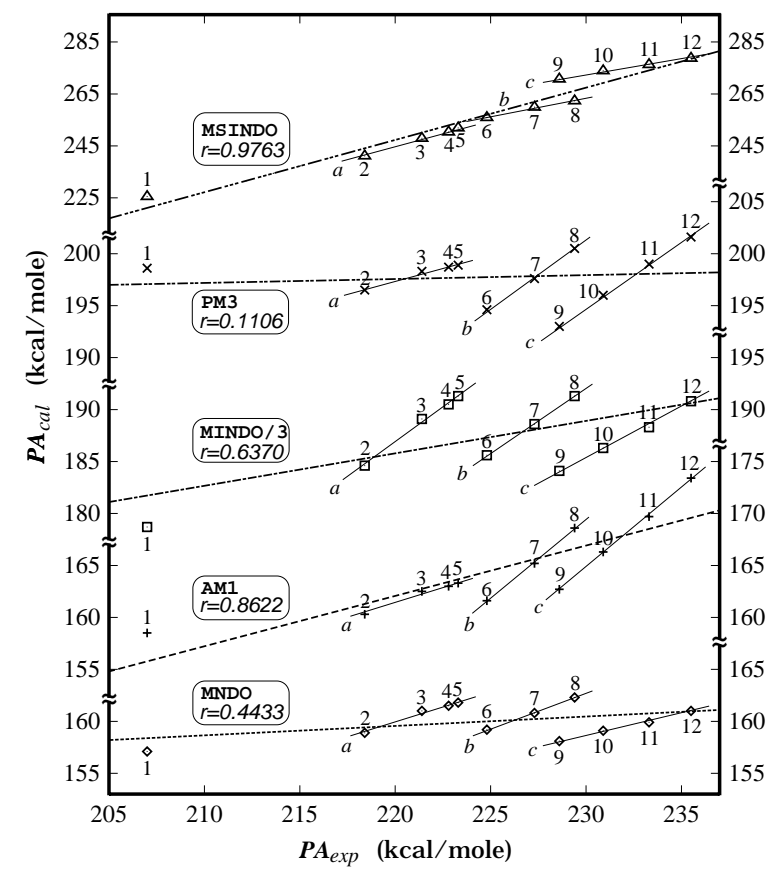

Fig. 5. Plots of proton affinities $\left(\mathrm{PA}_{\text {cal }}, 298 \mathrm{~K}\right)$ calculated with the most common semiempirical methods (MSINDO, PM3, AM1, MNDO, MINDO/3) vs. experimental values $\left(\mathrm{PA}_{\mathrm{exp}}\right)$ in $\mathrm{kcal} / \mathrm{mol}$. Lines $a, b$, and $c$ show the correlations within the groups of primary, secondary and tertiary amines. For numbering of compounds see Figure 1.

To evaluate the effect of geometry optimization we repeated these semiempirical calculations using standard structural parameters [20] (Table 3, Figure 6).

It is interesting to note that the MINDO/3- and AM1 results obtained using standard geometries cor- 
Table 3. Measured $\left(\mathrm{PA}_{\mathrm{ex}}\right)$ and calculated proton affinties (in $\mathrm{kcal} / \mathrm{mol}$ ). All proton affinities have been calculated for standard geometries.

\begin{tabular}{|c|c|c|c|c|c|c|c|c|}
\hline No. & $\begin{array}{l}\text { Molec- } \\
\text { ule }\end{array}$ & $\mathrm{PA}_{\mathrm{ex}}$ & $\begin{array}{c}\mathrm{MIN} \\
\mathrm{DO} / 3\end{array}$ & $\begin{array}{l}\text { MN } \\
\text { DO }\end{array}$ & AM1 & PM3 & $\begin{array}{c}\text { MSI } \\
\text { NDO }\end{array}$ & EHT \\
\hline 1 & $\mathrm{NH}_{3}$ & 207.0 & 179.0 & 157.9 & 158.3 & 198.7 & 224.0 & 148.8 \\
\hline 2 & $\mathrm{MeNH}_{2}$ & 218.4 & 186.6 & 157.5 & 160.5 & 196.1 & 239.2 & 150.8 \\
\hline 3 & $\mathrm{EtNH}_{2}{ }^{2}$ & 221.4 & 191.1 & 159.7 & 162.6 & 197.9 & 244.9 & 151.3 \\
\hline 4 & $n-\mathrm{PrNH}_{2}$ & 222.8 & 193.5 & 160.5 & 163.2 & 198.5 & 247.5 & 151.3 \\
\hline 5 & $n$-BuNH & 223.3 & 194.7 & 160.8 & 163.6 & 198.7 & 248.9 & 151.3 \\
\hline 6 & $\mathrm{Me}_{2} \mathrm{NH}$ & 224.8 & 190.7 & 156.4 & 161.9 & 193.4 & 254.3 & 152.2 \\
\hline 7 & MeEtNH & 227.3 & 192.6 & 157.1 & 164.7 & 196.0 & 256.3 & 152.5 \\
\hline 8 & $\mathrm{Et}_{2} \mathrm{NH}$ & 229.4 & 194.3 & 157.8 & 167.4 & 198.5 & 257.9 & 152.8 \\
\hline 9 & $\mathrm{Me}_{3} \mathrm{~N}$ & 228.6 & 192.3 & 154.8 & 162.7 & 190.8 & 269.1 & 153.2 \\
\hline 10 & $\mathrm{Me}_{2} \mathrm{EtN}$ & 230.9 & 193.8 & 155.4 & 165.2 & 193.3 & 270.1 & 153.5 \\
\hline 11 & $\mathrm{MeEt}_{2} \mathrm{~N}$ & 233.3 & 194.9 & 155.8 & 167.6 & 195.7 & 270.8 & 153.7 \\
\hline 12 & $\mathrm{Et}_{3} \mathrm{~N}$ & 235.5 & 196.1 & 156.2 & 169.9 & 198.0 & 271.6 & 153.9 \\
\hline
\end{tabular}

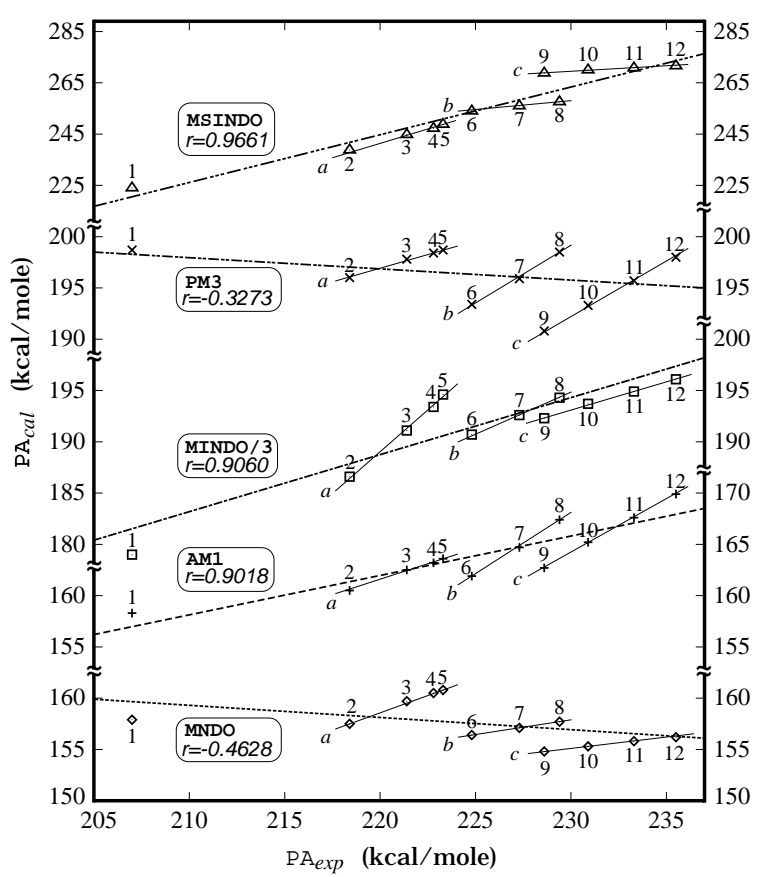

Fig. 6. Plots of proton affinities $\left(\mathrm{PA}_{\mathrm{cal}}, 298 \mathrm{~K}\right)$ calculated with the most common semiempirical methods employing standard geometries (MSINDO, PM3, AM1, MNDO, $\mathrm{MINDO} / 3)$ vs. experimental values $\left(\mathrm{PA}_{\text {exp }}\right)$ in $\mathrm{kcal} / \mathrm{mol}$. Lines $a, b$, and $c$ show the correlations within the groups of primary, secondary and tertiary amines. For numbering of compounds see Figure 1.

relate slightly (AM1) or significantly (MINDO/3) better with the experimental values than those obtained from fully optimized structures. Note that at this level

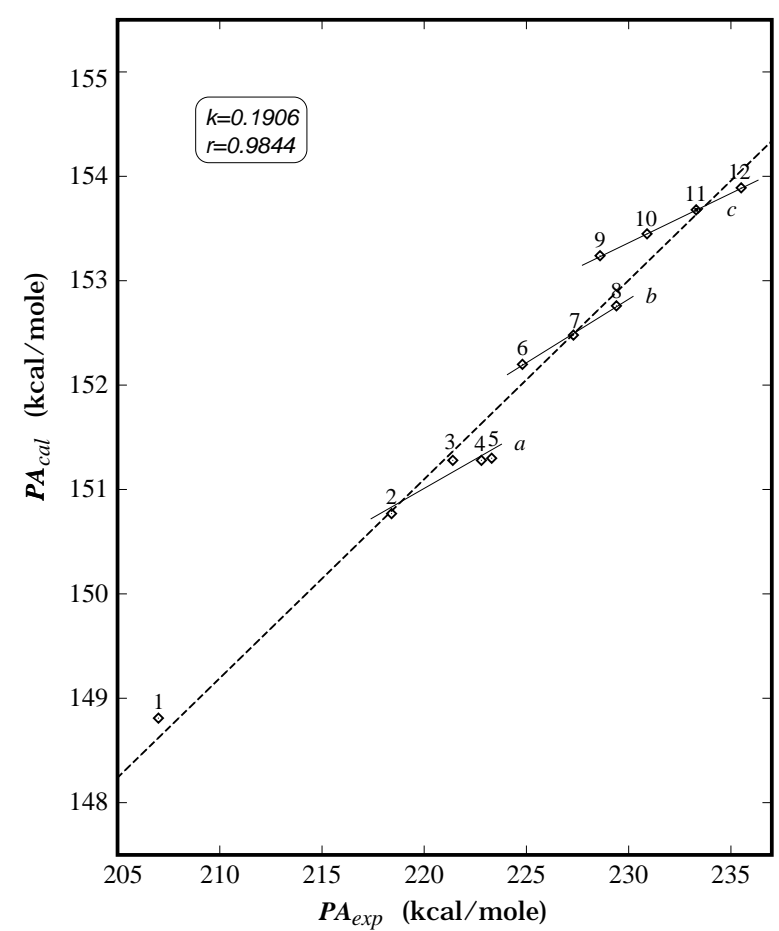

Fig. 7. Plots of proton affinities $\left(\mathrm{PA}_{\text {cal }}, 298 \mathrm{~K}\right)$ calculated with the non-iterative EHT method employing standard geometries vs. experimental values $\left(\mathrm{PA}_{\mathrm{exp}}\right)$ in $\mathrm{kcal} / \mathrm{mol}$. Lines $a, b$, and $c$ show the correlations within the groups of primary, secondary and tertiary amines. For numbering of compounds see Figure 1.

MINDO/3 also gives the correct order of proton affinities for $\mathrm{RNH}_{2}, \mathrm{R}_{2} \mathrm{NH}$, and $\mathrm{R}_{3} \mathrm{~N}(\mathrm{R}=\mathrm{Me}, \mathrm{Et})$. We therefore conclude that geometry optimizations are of no general advantage in the calculation of proton affinities of amines with either the MINDO/3or AM1 method. The overall correlation obtained with MSINDO remains essentially unchanged while the MNDO- and PM3 results are significantly worse when standard geometries are used.

Surprisingly, even the noniterative extended Hückel theory yields an overall correlation which is much better than those obtained with MINDO/3, MNDO, AM1, and PM3 (Table 3, Fig. 7) ( $\triangle \mathrm{PA}=$ $73.1 \mathrm{kcal} / \mathrm{mol}$ ). Again, the measured order of the proton affinities of the methyl- and ethyl amines is reproduced correctly.

Surprising results have also been obtained with the CNDO- and INDO methods (Table 4, Figure 8). While the absolute values of the proton affinities calculated by means of the CNDO/2-, INDO-, CNDO/2S-, 
Table 4. Measured $\left(\mathrm{PA}_{\mathrm{ex}}\right)$ and calculated proton affinties (in $\mathrm{kcal} / \mathrm{mol}$ ). All proton affinities have been calculated for standard geometries. The $\mathrm{CNDO} / 2^{\prime}$ values have been calculated using reoptimized parameters for $\mathrm{H}, \mathrm{C}$, and $\mathrm{N}$.

\begin{tabular}{llllllll}
\hline No. Molec. & \multicolumn{6}{c}{$\mathrm{PA}_{\mathrm{ex}} \mathrm{CNDO} / 2 \mathrm{INDO} \mathrm{CNDO} / 2 \mathrm{~S}$ INDO/2S CNDO/2' } \\
\hline 1 & $\mathrm{NH}_{3}$ & 207.0 & 291.8 & 312.9 & 496.7 & 522.0 & \\
2 & $\mathrm{MeNH}_{2}$ & 218.4 & 304.5 & 323.8 & 502.0 & 527.0 & 301.1 \\
3 & $\mathrm{EtNH}_{2}$ & 221.4 & 311.9 & 331.3 & 504.0 & 528.8 & 308.6 \\
4 & $n-\mathrm{PrNH}_{2}$ & 222.8 & 314.7 & 334.1 & 505.1 & 529.8 & 311.3 \\
5 & $n-\mathrm{BuNH}_{2}$ & 223.3 & 316.0 & 335.4 & 505.6 & 530.3 & 312.6 \\
6 & $\mathrm{Me}_{2} \mathrm{NH}$ & 224.8 & 313.8 & 331.3 & 506.3 & 531.2 & 315.7 \\
7 & $\mathrm{MeEtNH}_{2} 22.3$ & 318.0 & 335.1 & 507.8 & 532.4 & 319.8 \\
8 & $\mathrm{Et}_{2} \mathrm{NH}$ & 229.4 & 321.7 & 338.6 & 509.2 & 533.5 & 323.5 \\
9 & $\mathrm{Me}_{3} \mathrm{~N}$ & 228.6 & 320.8 & 336.3 & 509.7 & 534.9 & 321.4 \\
10 & $\mathrm{Me}_{2} \mathrm{EtN}$ & 230.9 & 324.2 & 339.5 & 511.1 & 536.0 & 324.8 \\
11 & $\mathrm{MeEt}_{2} \mathrm{~N}$ & 233.3 & 327.3 & 342.4 & 512.6 & 537.1 & 327.9 \\
12 & $\mathrm{Et}_{3} \mathrm{~N}^{2}$ & 235.5 & 330.2 & 345.2 & 513.9 & 538.1 & \\
\hline
\end{tabular}

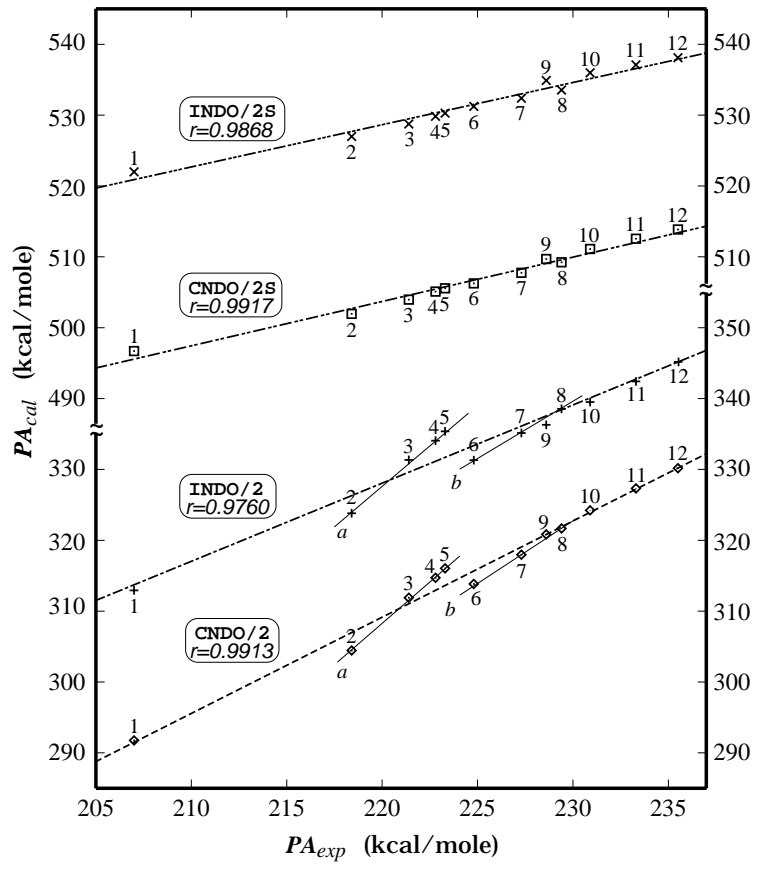

Fig. 8. Plots of proton affinities $\left(\mathrm{PA}_{\text {cal }}, 298 \mathrm{~K}\right)$ calculated with the semiempirical methods $\mathrm{CNDO} / 2$, INDO/2, $\mathrm{CNDO} / 2 \mathrm{~S}$, and INDO/2S employing standard geometries $v s$. experimental values $\left(\mathrm{PA}_{\text {exp }}\right)$ in $\mathrm{kcal} / \mathrm{mol}$. Lines $a$ and $b$ show the correlations within the groups of primary and secondary amines. For numbering of compounds see Figure 1.

and INDO/2S theory using standard geometries differ significantly from their experimental counterparts $(\Delta \mathrm{PA}=91.0,108.6,281.8$, and $306.5 \mathrm{kcal} / \mathrm{mol})$, the overall correlations are much better than those ob-

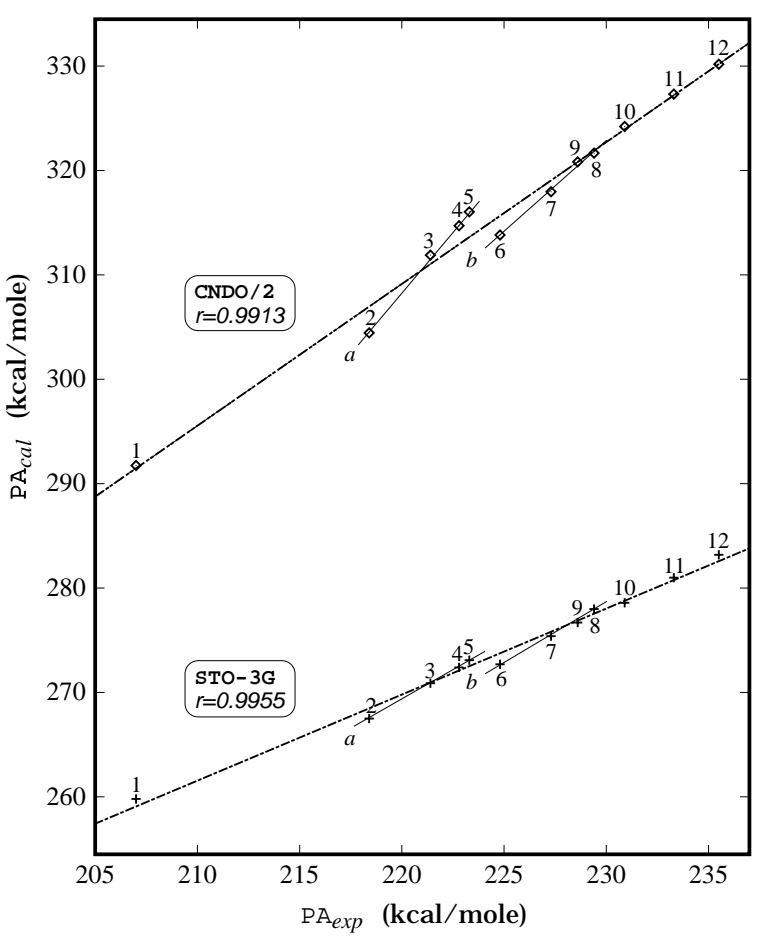

Fig. 9. Comparion of correlations obtained at the HF/STO$3 \mathrm{G}$ and $\mathrm{CNDO} / 2$ level. Proton affinities in $\mathrm{kcal} / \mathrm{mol}$. Lines $a$ and $b$ show the correlations within the groups of primary and secondary amines. For numbering of compounds see Figure 1.

tained with MINDO/3, MNDO, AM1, and PM3. Especially the order of the proton affinities of $\mathrm{RNH}_{2}$, $\mathrm{R}_{2} \mathrm{NH}$, and $\mathrm{R}_{3} \mathrm{~N}(\mathrm{R}=\mathrm{Me}, \mathrm{Et})$ is reproduced correctly by all four methods. Similar ${ }^{\mathrm{b})} \mathrm{CNDO} / 2$ proton affinities have been obtained by Tollenaere and Moereels [28]. The same authors also report the results of PCILO calculations for a variety of amines which resulted in an excellent correlation between measured and calculated proton affinities. Most of the PCILO PAs are slightly higher than the corresponding $\mathrm{CNDO} / 2$ values.

The overall correlation obtained with the CNDO/2 method is strikingly similar to that from our HF/STO3G calculations (Fig. 9). This might be due to the fact that the CNDO/2 parameters have been chosen in such a way as to reproduce some results of nonempirical calculations using a minimal basis set [20].

\footnotetext{
b) The CNDO/2 proton affinities in [28] are on the average $3.8 \mathrm{kcal} / \mathrm{mol}$ higher than our values, since the N-H bond lengths in the cations have been optimized.
} 


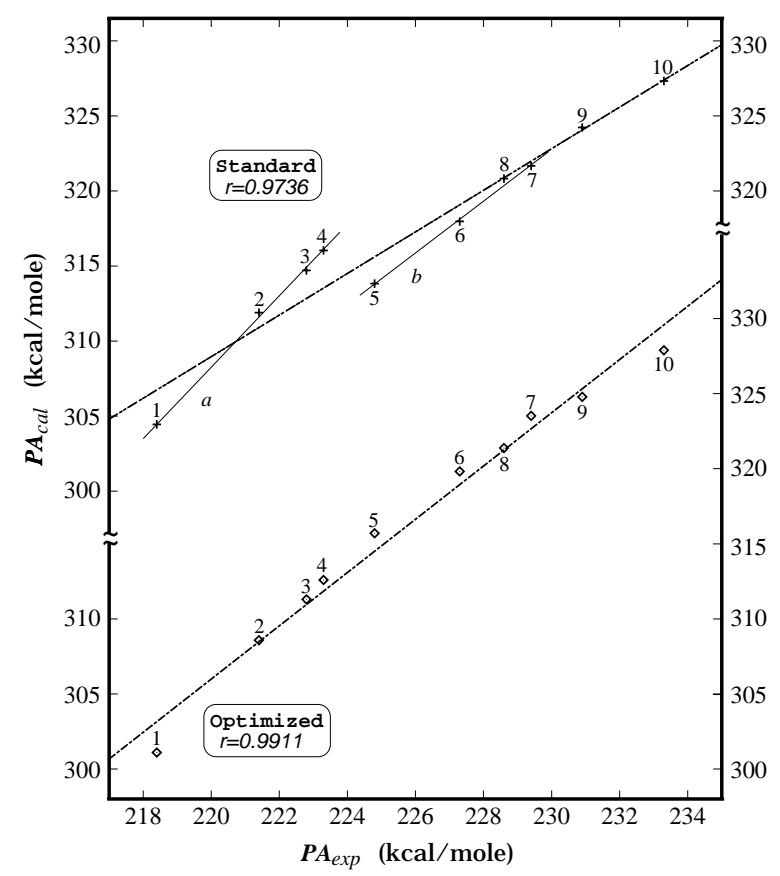

Fig. 10. Comparion of correlations obtained with the CNDO/2 method employing standard (upper line) an reoptimized $U_{\mu \mu}$ parameters (lower line). Proton affinities in $\mathrm{kcal} / \mathrm{mol}$. Lines $a$ and $b$ show the correlations within the groups of primary and secondary amines. For numbering of compounds see Figure 1.

We now turned our attention to the question why some of the semiempirical methods perform poorly in the calculation of proton affinities. Within the framework of most semiempirical methods it is assumed that the basis set consists of Löwdin orbitals $\left(\chi^{\mathrm{L}}\right)$ although this is merely reflected by the neglect of certain integrals containing differential overlap. However, the

[1] (a) J. J. P. Stewart, J. Comput. Chem. 10, 209 (1989); (b) J. Comput. Chem. 10, 221 (1989).

[2] M. J. S. Dewar, E. G. Zoebisch, E. F. Healy, and J. J. P. Stewart, J. Amer. Chem. Soc. 107, 3902 (1985).

[3] (a) M. J. S. Dewar and W. Thiel, J. Amer. Chem. Soc. 99, 4899 (1977); (b) J. Am. Chem. Soc. 99, 4907 (1977); (c) S. Olivella, F. Urpí, and J. Vilarrasa, J. Comput. Chem. 3, 230 (1984).

[4] (a) R. C. Bingham, M. J. S. Dewar, and D. H. Lo, J. Amer. Chem. Soc. 97, 1285 (1975); (b) J. Amer. Chem. Soc. 97, 1302 (1975).

[5] (a) B. Ahlswede and K. Jug, J. Comput. Chem. 20, 563 (1999); (b) J. Comput. Chem. 20, 572 (1999).
Table 5. Optimized CNDO/2 $U_{\mu \mu}$ parameters for the hydrogen-, carbon-, and nitrogen atoms of primary, secondary, and tertiary amines together with the standard values (in e. V.).

\begin{tabular}{lrrrc}
\hline Parameter & Primary & Secondary & Tertiary & Standard \\
\hline$U_{1 \mathrm{~s} 1 \mathrm{~s}, \mathrm{H}}$ & -6.966 & -6.966 & -6.966 & -7.1761 \\
$U_{2 \mathrm{~s} 2 \mathrm{~s}, \mathrm{C}}$ & -14.057 & -14.057 & -14.057 & -14.051 \\
$U_{2 \mathrm{p} 2 \mathrm{p}, \mathrm{C}}$ & -5.819 & -5.819 & -5.819 & -5.572 \\
$U_{2 \mathrm{~s} 2 \mathrm{~s}, \mathrm{~N}}$ & -19.978 & -18.745 & -19.134 & -19.3163 \\
\hline
\end{tabular}

fact that a Löwdin orbital of an atom has satellites at its neighbours is neglected when atomic parameters are derived. Thus, for example, the same parameter $U_{\mu \mu}$ is used for the orbital $\mu$ of a nitrogen atom regardless whether this atom is part of a primary, secondary, or tertiary amine. To take into account the different nature of primary, secondary and tertiary nitrogen atoms we then reoptimized the $U_{\mu \mu}$ parameters for $\mu=1 \mathrm{sH}, 2 \mathrm{sC}, 2 \mathrm{pC}, 2 \mathrm{sN}$, and $2 \mathrm{pN}$ regarding the proton affininities. In this way we determined the separate values for the $\mathrm{N}$ atoms in primary, secondary, and tertiary amines which are listed in Table 5. Use of these new parameters results in the proton affinities given in the last colum of Table 4 . The corresponding correlation is shown in Fig. 10 (lower line). In order to demonstrate the improvement we also included the corresponding plot obtained using standard CNDO/2 parameters (upper line).

\section{Acknowledgement}

The authors gratefully acknowledge financial support by the Fonds der Chemischen Industrie and technical assistance by the Rechenzentrum der RWTH Aachen.

[6] (a) J. A. Pople, D. P. Santry, and G. A. Segal, J. Chem. Phys. 43, S129 (1965); (b) J. A. Pople and G. A. Segal, J. Chem. Phys. 43, S136 (1965); (c) J. A. Pople and G. A. Segal, J. Chem. Phys. 44, 3289 (1966); (d) D. P. Santry and G. A. Segal, J. Chem. Phys. 47, 158 (1967).

[7] J. A. Pople, D. L. Beveridge, and P. A. Dobosh, J. Chem. Phys. 47, 2026 (1967).

[8] J. Del Bene and H. H. Jaffé, J. Chem. Phys. 48, 1807 (1968).

[9] (a) J. Ridley and M. Zerner, Theor. Chim. Acta 32, 111 (1973); (b) Theor. Chim. Acta 42, 223 (1976). 
[10] (a) R. Hoffmann, J. Chem. Phys. 39, 1397 (1963); (b) M. Wolfsberg and L. Helmholz, J. Chem. Phys. 20, 837 (1952).

[11] (a) D. H. Aue, H. M. Webb, and M. T. Bowers, J. Amer. Chem. Soc. 98, 318 (1976); (b) J. Amer. Chem. Soc. 98, 311 (1976).

[12] Gaussian 98, Revision A. 7, M. J. Frisch, G. W. Trucks, H. B. Schlegel, G. E. Scuseria, M. A. Robb, J. R. Cheeseman, V. G. Zakrzewski, J. A. Montgomery, Jr., R. E. Stratmann, J. C. Burant, S. Dapprich, J. M. Millam, A. D. Daniels, K. N. Kudin, M. C. Strain, O. Farkas, J. Tomasi, V. Barone, M. Cossi, R. Cammi, B. Mennucci, C. Pomelli, C. Adamo, S. Clifford, J. Ochterski, G. A. Petersson, P. Y. Ayala, Q. Cui, K. Morokuma, D. K. Malick, A. D. Rabuck, K. Raghavachari, J. B. Foresman, J. Cioslowski, J. V. Ortiz, A. G. Baboul, B. B. Stefanov, G. Liu, A. Liashenko, P. Piskorz, I. Komaromi, R. Gomperts, R. L. Martin, D. J. Fox, T. Keith, M. A. Al-Laham, C. Y. Peng, A. Nanayakkara, C. Gonzalez, M. Challacombe, P. M. W. Gill, B. Johnson, W. Chen, M. W. Wong, J. L. Andres, C. Gonzalez, M. Head-Gordon, E. S. Replogle, and J. A. Pople, Gaussian, Inc., Pittsburgh PA, USA 1998.

[13] TURBOMOLE (Version 5), R. Ahlrichs, M. Bär, H.-P. Baron, R. Bauerschmitt, S. Böcker, M. Ehrig, K. Eichkorn, S. Elliott, F. Furche, F. Haase, M. Häser, H. Horn, C. Huber, U. Huniar, M. Kattannek, C. Kölmel, M. Kollwitz, K. May, C. Ochsenfeld, H. Öhm, A. Schäfer, U. Schneider, O. Treutler, M. von Arnim, F. Weigend, P. Weis, and H. Weiss, Quantum Chemistry Group, University of Karlsruhe, Germany 1998.
[14] MOPAC Version 6.0. QCPE 455, J. J. P. Stewart (1990). Indiana University, Bloomington, IN, USA.

[15] QCMP001, J. D. Bowden, and G. S. Owen; modification of QCPE 141, P. A. Dobosh and N. C. Baird.

[16] DZDO, J. W. Downing, and J. Michl, University of Colorado at Boulder.

[17] MSINDO (Version 1.0), B. Ahlswede, and K. Jug, University of Hannover, Germany 1999.

[18] C. Hillebrand, M. Klessinger, M. Eckert-Maksić, and Z. B. Maksić, J. Phys. Chem. 100, 9698 (1996).

[19] B. J. Smith and L. Radom, J. Phys. Chem. 99, 6468 (1995).

[20] J. A. Pople and D. L. Beveridge, Approximate Molecular Orbital Theory, McGraw-Hill Inc., New York 1970.

[21] E. Heyne, H. Niephaus, G. Raabe, W. Schleker, J. Fleischhauer, Z. Naturforsch. 40a, 1143 (1985).

[22] E. Heyne, G. Raabe, and J. Fleischhauer, Z. Naturforsch. 39a, 593 (1984).

[23] J. P. Perdew, Phys. Rev. B. 33, 8822 (1986).

[24] M. J. S. Dewar and K. M. Dieter, J. Amer. Chem. Soc. 108, 8075 (1986).

[25] J. J. Novoa, J. Mol. Struct. (Theochem) 136, 361 (1986).

[26] G. P. Ford, J. D. Scribner, J. Comput. Chem. 4, 594 (1983).

[27] D. H. Everett and W. F. K. Wynne-Jones, Proc. Roy. Soc. London A177, 499 (1941).

[28] J. P. Tollenaere and H. Moereels, Tetrahedron Lett. 15, 1347 (1978). 